\title{
Study of pattern of hearing loss in CSOM (chronic suppurative OTITIS media)
}

\author{
Moruskar A. ${ }^{1}$, Karodpati N. ${ }^{2}$, Ingale M. ${ }^{3}$, Shah S. ${ }^{4}$ \\ ${ }^{1}$ Dr Aditi Moruskar, Assistant Professor, ${ }^{2}$ Dr Nayanna Karodpati, Associate Professor, ${ }^{3}$ Dr Mayur Ingale, \\ Assistant Professor, ${ }^{4}$ Dr Shikha Shah, Resident, all authors are attached with Department of ENT, Dr. D Y \\ Patil Hospital \& Research Centre, DPU, Pune, India.
}

Corresponding Author: Dr Nayanna Karodpati, Associate Professor, Department of ENT, Dr. D Y Patil Hospital \& Research Centre, DPU, Pune, India.

\begin{abstract}
Introduction: Chronic suppurative otitis media is one of the most common conditions encountered by Otologists in daily practice. Conventionally hearing loss in CSOM is conductive in nature, but it has been observed that some patient displayed an additional sensorineural component to their conductive hearing loss (mixed hearing loss). Material and Methods: A prospective cohort observational study on 100 Cases in two groups of 50 each who had safe CSOM and 50 unsafe CSOM conducted over a period of July 2011 to September 2013 at the Department of Otorhinolaryngology, Padmashree Dr. D. Y. Patil Medical College, Hospital and Research Centre (DPU), Pimpri, Pune. Detailed history, complete ENT examination was done. They were then subjected to Puretone audiometry; air and bone conduction thresholds were tested and plotted on the audiogram. Univariate and multivariate logistic regression (odds ratio) analyses were used. Results: Incidence of hearing loss is $72 \%$ for conductive type and $28 \%$ is of mixed type, in which $72 \%$ are of safe conductive, $18 \%$ safe mixed type and $64 \%$ are of unsafe conductive, $36 \%$ are in unsafe mixed type. Incidence of SNHL increases as age increases being maximum in age group of $41-50$ years i.e. $37.50 \%$ and minimum in 11-20 years i.e. $5.71 \%$. $14 \%$ cases of unsafe chronic suppurative otitis media were found to be associated with labyrinthine fistula. This proved to be the commonest cause of sensorineural component in unsafe chronic suppurative otitis media followed by granulation over oval window (8\%) and cholesteatoma extending to round window in $4 \%$ of cases. Conclusion: In the present study incidence of sensorineural hearing loss increased with advancing age, showing that age is a risk factor for sensorineural component of hearing loss in CSOM though conductive hearing loss is more common. CSOM is associated with mixed hearing loss mainly $>35 \mathrm{~dB}$, higher frequencies were involved.
\end{abstract}

Keywords: Chronic suppurative otitis media, Hearing Loss, Sensorineural hearing loss

\section{Introduction}

Otitis media is an important and a highly prevalent disease of the middle ear and poses serious health problem worldwide especially in developing countries where large percentage of the population lack specialized medical care, suffer from malnutrition and live in poor hygienic environmental conditions [1].

Manuscript received: $28^{\text {th }}$ May 2019

Reviewed: $08^{\text {th }}$ June 2019

Author Corrected: $13^{\text {th }}$ June 2019

Accepted for Publication: $18^{\text {th }}$ June 2019
Chronic suppurative otitis media is a persistent inflammation of the middle ear or mastoid cavity, and is characterised by recurrent or persistent ear discharge through a perforation of the tympanic membrane [2]. In spite of the fact that the complications of CSOM can be fatal [3, 4], hearing impairment is regarded the main health issue. Furthermore, the conductive hearing impairment resulting from this condition has been well acknowledged in the literature [5]. 


\section{Original Research Article}

However, the relationship between sensorineural hearing loss (SNHL) and CSOM remains a controversial issue.

CSOM is the most chronic infectious disease in children [6] and is considered the leading cause of acquired hearing loss [7].

In many studies it is found that many cases of safe as well as unsafe type of chronic suppurative otitis media without complications, shows a sensorineural element also. In some cases even dead ears are seen in safe type of chronic suppurative otitis media [8].

With this background present study was planned to study of pattern of hearing loss in CSOM in Indian Population. Hearing loss as a sequel of chronic suppurative otitis media (CSOM) is often conductive, but recent studies have found an additional sensorineural component in these patients, thus demonstrating inner ear damage [9].

Children with mixed hearing loss invariably suffer from the point of view of education and development of language and therefore it becomes essential to study such cases so that sensorineural deafness in CSOM can be prevented.

Children with mixed hearing loss invariably suffer from the point of view of education and development of language and therefore it becomes essential to study such cases so that sensorineural deafness in CSOM can be prevented.

The present study was an attempt to study pattern of hearing loss in CSOM and clinical factors if any that might affect sensorineural component.

\section{Material and Methods}

The present study was an prospective cohort observational study on 100 Cases in two groups of 50 each who had safe CSOM and 50 unsafe CSOM. Conducted over a period of July 2011 to September 2013 at the Department of Otorhinolaryngology, Padmashree Dr. D. Y. Patil Medical College, Hospital and Research Centre (DPU), Pimpri, Pune.
Study design - Observational study

Inclusion criteria- All CSOM cases with copious ear discharge, central perforation on otoscopy. were included in the safe group and all cases with scanty discharge foul smelling, attic or marginal perforation, granulation tissue or cholesteatoma on otoscopy were included in the unsafe group.

Exclusion criteria - Age below 1 year and above 50 years, Prior ontological surgery, History of head injury, Acoustic trauma, Traumatic tympanic membrane perforation, Systemic ototoxic drugs, cardiovascular and metabolic disease, and hereditary causes were excluded from the study.

Collection of data- Detailed history was elicited; complete ENT examination was done to look for status of otorrhoea, type of perforation, ossicular disruption and presence of granulation tissue or cholesteatoma.

They were then subjected to Puretone audiometry, air and bone conduction thresholds were tested and plotted on the audiogram. Narrow band masking was used wherever appropriate. Aural swabs were collected and innoculated for culture and sensitivity.

Operative findings of all cases which underwent surgery were noted. Middle ear effusions at round window were observed. Changes at round window evident under microscope such as obliteration due to bone formation were noted. Presence of labyrinthine erosion or fistula was looked in suspected cases. Cases with labyrinthine fistula found at surgery or with positive fistula sign were documented. The duration of disease was considered on the basis of onset of otorrhoea except in cases of otitis media with effusion.

Statistical analysis- Continuous variables were described as means (95\% confidence interval) and the difference was observed by using $\mathrm{T}$ test. Differences for categorical variables were assessed by the chi-square test. Univariate and multivariate logistic regression (odds ratio [OR]) analyses were used to identify those variables associated with AKI and mortality. P-value $<0.05$ was considered significant. 


\section{Results}

Table No-1: Pattern of hearing loss

\begin{tabular}{|c|c|c|c|}
\hline Type of hearing loss & Incidence $(\mathbf{n}=\mathbf{1 0 0})$ & Safe $(\mathbf{n}=\mathbf{5 0})$ & Unsafe $(\mathbf{n}=\mathbf{5 0})$ \\
\hline Conductive & $72 \%$ & $82 \%$ & $64 \%$ \\
\hline Mixed & $28 \%$ & $18 \%$ & $36 \%$ \\
\hline
\end{tabular}

Incidence of hearing loss was observed to be $72 \%$ for conductive type and $28 \%$ was of mixed type, in which $72 \%$ were of safe conductive, $18 \%$ of safe mixed type and $64 \%$ were of unsafe conductive, $36 \%$ were in unsafe mixed type.

Table No-2: Incidence of SNHL in different age groups

\begin{tabular}{|c|c|c|}
\hline Age group of patients & No. of patients with CSOM & $\begin{array}{c}\text { Incidence of SN component of } \\
\text { hearing loss }\end{array}$ \\
\hline $11-20$ & 35 & $2(5.71 \%)$ \\
\hline $21-30$ & 25 & $4(16.00 \%)$ \\
\hline $31-40$ & 24 & $5(20.81 \%)$ \\
\hline $41-50$ & 16 & $6(37.50 \%)$ \\
\hline Total & $\mathbf{1 0 0}$ & \\
\hline
\end{tabular}

Incidence of SNHL increased as age increased, the maximum incidences being in age group of 41-50 years i.e. $37.50 \%$ and minimum in $11-20$ years i.e. $5.71 \%$.

Mean bone conduction thresholds were deduced at different frequencies and tabulated against duration of CSOM. This study found grater incidence of hearing loss with increasing duration of disease, Hence, the incidence of SNHL component has correlation with duration of disease.

Table No-3: Correlation of SNHL component with duration of CSOM

\begin{tabular}{|c|c|c|c|c|c|c|}
\hline & \multicolumn{5}{|c|}{ Duration of CSOM (In Months) } & \\
\hline Deafness & Upto12 & $\mathbf{1 3 - 2 4}$ & $\mathbf{2 5 - 3 6}$ & $\mathbf{3 7 - 4 8}$ & $\mathbf{4 9 - 6 0}$ & No. of Cases \\
\hline $20-25 \mathrm{~dB}$ & 1 & 0 & 0 & 1 & 0 & 2 \\
\hline $26-30 \mathrm{~dB}$ & 0 & 2 & 0 & 1 & 1 & 4 \\
\hline $31-35 \mathrm{~dB}$ & 0 & 0 & 1 & 1 & 0 & 2 \\
\hline$>35 \mathrm{~dB}$ & 0 & 3 & 3 & 3 & 0 & 9 \\
\hline
\end{tabular}

In the present study, $14 \%$ cases of unsafe chronic suppurative otitis media were found to be associated with labyrinthine fistula. This proved to be the commonest cause of sensorineural component in unsafe chronic suppurative otitis media followed by granulation over oval window (8\%) and cholesteatoma extending to round window in $4 \%$ of cases. There were 4 cases with sensorineural hearing loss in safe CSOM group, the cause of which could not be ascertained.

Table No.-4: Causes of SNHL in unsafe CSOM

\begin{tabular}{|c|c|c|}
\hline Causes of SNHL in unsafe CSOM & No. of Pts & \% (n=50) \\
\hline Cholesteatoma extending upto round window & 2 & $4 \%$ \\
\hline Labyrinthine fistula & 7 & $14 \%$ \\
\hline Granulations over oval window & 4 & $8 \%$ \\
\hline
\end{tabular}




\section{Discussion}

In the present study, Sensorineural loss, either alone or with conductive loss may occur in acute as well as chronic suppurative otitis media. 100 cases of chronic suppurative otitis media were examined clinically and with the aid of audiometry showed 17 patients with mixed hearing loss.

Incidence of hearing loss was observed to be $72 \%$ for conductive type and $28 \%$ of mixed type, in which $72 \%$ were of safe conductive, $18 \%$ safe mixed type and $64 \%$ were of unsafe conductive, $36 \%$ were in unsafe mixed type, and the incidence of SNHL increased as age increased being maximum in age group of $41-50$ years i.e. $37.50 \%$ and minimum in $11-20$ years i.e. $5.71 \%$.

Amali A et al [9] found that older patients were more vulnerable to the effects of middle ear inflammation on cochlear function, and this vulnerability could lead to intense hearing impairment due to aging. Age-related hearing loss (ARHL) or presbycusis is one of the most common disabilities in elderly people, which affects approximately $27.6 \%$ of individuals between 65 to 79 years and $36.5 \%$ of those aged 80 and older.

Maharjan $\mathrm{M}$ et al [10] found one hundred patients with 119 perforated tympanic membrane, age ranged between 8 to 60 years, 44 males and 56 females were studied. Bilateral tympanic membrane perforation were seen in 19 patients, right sided perforation in 39 and left sided in 42 patients respectively. The longer the duration of ear discharge, the more the hearing loss.

In the present study, $14 \%$ cases of unsafe chronic suppurative otitis media were found to be associated with labyrinthine fistula.

This proved to be the commonest cause of sensorineural component in unsafe chronic suppurative otitis media followed by granulation over oval window (8\%) and cholesteatoma extending to round window in $4 \%$ of cases. There were 4 cases with sensorineural hearing loss in safe CSOM group, the cause of which could not be ascertained
In another studies, Silveira Netto LF et al [11] and Orji FT et al [12] found that air conduction, bone conduction thresholds and air-bone gaps in children and teenagers with CCOM were significantly greater. There were no significant differences between air-bone gaps in epitympanic and posterior mesotympanic cholesteatomas.

In NCCOM, the gap value is positively correlated with the number of quadrants with tympanic perforation. There was no significant difference between the air-bone gaps in tympanic perforations affecting the posterior and anterior quadrants. Redaelli de Zinis LO et al [12] observed that selected clinical features were assessed among diseased ears to examine possible influences on inner ear function. Mean bone conduction threshold differences varied from $0.6 \mathrm{~dB}$ at 0.5 $\mathrm{kHz}$ to $3.7 \mathrm{~dB}$ at $4 \mathrm{kHz}$.

These differences augmented with increasing duration of middle ear disease. Impaired hearing by bone conduction thresholds of diseased ears correlated with increased age at every frequency and with an interruption of the ossicular chain only at higher frequencies. The severity of sensorineural hearing loss correlated with longer duration of middle ear disease. Thus, surgical treatment of dry and apparently stable tympanic membrane perforation was warranted.

Papp Z et al [13] observed that chronic suppurative otitis media was seen to be associated with sensorineural hearing loss. When age and normal side were corrected for, pure-tone threshold and bone conduction threshold at either the speech frequencies or at $4 \mathrm{kHz}$ increased gradually according to the duration of the chronic suppurative otitis media. The threshold shift was more accentuated as age increased. The sensorineural hearing loss at $4 \mathrm{kHz}$ seemed to be higher than that at the speech frequencies. The findings from the present study were consistent with those found in several studies $[14,15]$. In a study with similar methodology, SNHL was progressively increased with increasing the CSOM duration [16]. 


\section{Original Research Article}

The inner ear is vulnerable against chronic suppurative otitis media. Older age increases this vulnerability. The proximity of the sensory cells to the potential source of harm (inflamed middle ear) may mean higher exposure, as reflected by the fact that sensory cells processing higher frequencies are more seriously damaged [13]. Cholesteatoma is a mass in the tympanic cavity and/or mastoid cavity, formed by keratinising squamous epithelium, subepithelial connective tissue and the progressive accumulation of keratin debris with or without a surrounding inflammatory reaction. Surgery was the treatment of choice and its objectives were complete removal of the disease, creation of a safe, dry, and disease-free ear, and preservation or restoration of hearing as far as possible $[17,18]$.

\section{Conclusion}

In the present study incidence of sensorineural hearing loss increased with advancing age, showing that age is a risk factor for sensorineural component of hearing loss in CSOM. CSOM is associated with mixed hearing loss mainly $>35 \mathrm{~dB}$, higher frequencies were involved. Greater sensorineural hearing loss was found in patients of CSOM with cholesteatoma and labyrinthine fistula was commonest cause of sensorineural component in unsafe CSOM. However, these findings demonstrate significant audiometric cochlear damage; clinical relevancy should be evaluated in future studies.

\section{Funding: Nil, Conflict of interest: Nil Permission from IRB: Yes}

\section{References}

1. Nishant Kumar, Devashri Chilke Clinical Profile of Tubotympanic CSOM and Its Management With Special Reference to Site and Size of Tympanic Membrane Perforation, Eustachian Tube Function and Three Flap Tympanoplasty. Indian J Otolaryngol Head Neck Surg. 2012 Mar; 64 (1): 5-12. Published online $2011 \mathrm{Jul}$ 6. doi: $10.1007 / \mathrm{s} 12070-010-0114-5$

2. Acuin J. Review Extracts from Concise clinical evidence: Chronic suppurative otitis media.vBMJ. 2002 Nov 16; 325(7373):1159; discussion 1159.
3. Miura MS, Krumennauer RC, Lubianca Neto JF Intracranial complications of chronic suppurative otitis media in children. Braz J Otorhinolaryngol. 2005 Sep-Oct; 71 (5):639-43.

4. Mostafa BE, El Fiky LM, El Sharnouby MM.Complications of suppurative otitis media: still a problem in the 21 st century. ORL J Otorhinolaryngol Relat Spec. 2009; 71(2):87-92.

5. Mills RP (1997) Management of chronic suppurative otitis media. In: Kerr AG, Booth JB (eds) Scott-Brown's otolaryngology, vol. 3, 6th edn. Butterwoth-Heinemann, Oxford, $p$ 3/10/4 [Ref list]

6. Verhoeff M, van der Veen EL, Rovers MM, Sanders EA, Schilder AG. Chronic suppurative otitis media: a review. Int $J$ Pediatr Otorhinolaryngol. $2006 \mathrm{Jan} ;$ 70(1):1-12.

7. Jensen RG, Koch A, Homøe P.The risk of hearing loss in a population with a high prevalence of chronic suppurative otitis media. Int J Pediatr Otorhinolaryngol. 2013 Sep; 77 (9): 1530-5. [PubMed]

8. Miura MS, Krumennauer RC, Lubianca Neto JF (2005) Intracranial complications of chronic suppurative otitis media in children. Braz $J$ Otorhinolaryngol 71 (5): 639-643.[PubMed].

9. Amali A, Hosseinzadeh N, Samadi S Sensorineural hearing loss in patients with chronic suppurative otitis media: Is there a significant correlation? Electron Physician. 2017 Feb 25;9(2): 3823-3827. doi: 10. 19082/3823. eCollection 2017 Feb.

10. Maharjan M, Kafle P, Bista M, Shrestha $\mathrm{S}$, Toran KC. Observation of hearing loss in patients with chronic suppurative otitis media tubotympanic type. Kathmandu Univ Med J (KUMJ). 2009 Oct-Dec;7(28):397-401.

11. Silveira Netto $\mathrm{LF}^{1}$, da Costa SS, Sleifer P, Braga ME.The impact of chronic suppurative otitis media on children's and teenagers' hearing. Int J Pediatr Otorhinolaryngol. 2009 Dec;73 


\section{Original Research Article}

(12):1751-6. doi: 10.1016/j.ijporl. 2009.09.033 . Epub 2009 Oct 23.

12. Orji FT, Agu CC.Patterns of hearing loss in tympanic membrane perforation resulting from physical blow to the ear: a prospective controlled cohort study. .Clin Otolaryngol. 2009 Dec;34(6): 526-32. doi: 10.1111/j.1749-4486.2009. 02035.x.

13. Redaelli de Zinis LO, Campovecchi C, Parrinello G Predisposing factors for inner ear hearing lossassociation with chronic otitis media. Int J Audiol. 2005 Oct; 44(10): 593-8.

\section{Papp Z, Rezes S, Jókay I, Sziklai I} Sensorineural hearing loss in chronic otitis media.Otol Neurotol. 2003 Mar; 24(2):141-4.

15. Kolo ES, Salisu AD, Yaro AM, Nwaorgu OG. Sensorineural hearing loss in patients with chronic suppurative otitis media. Indian J Otolaryngol Head Neck Surg. 2012 Mar; 64(1): 59-62.
16. Noordzij JP, Dodson EE, Ruth RA, Arts HA, Lambert PR.Chronic otitis media and sensorineural hearing loss: is there a clinically significant relation?Am J Otol. 1995 Jul; 16(4):420-3.

17. Kaur K, Sonkhya N, Bapna AS. Chronic suppurative otitis media and sensorineural hearing loss: Is there a correlation?Indian J Otolaryngol Head Neck Surg. 2003 Mar; 55(1):21-4.

18. Aslan Felek S, Islam A, Celik H, Demirci M, Samim E, Kose SK.The functional and anatomical results of the canal wall down tympanoplasty in extensive cholesteatoma. Acta Otolaryngol. 2009 Dec; 129(12):1388-94.

19. r. Pareschi, D. Lepera, and R. Nucci. Canal wall down approach for tympano-mastoid cholesteatoma: long-term results and prognostic factors .Acta Otorhinolaryngol Ital. 2019 Apr; 39(2): 122129.doi: 10.14639/0392-100X-2237

\section{How to cite this article?}

Moruskar A., Karodpati N., Ingale M., Shah S. Study of pattern of hearing loss in CSOM (chronic suppurative OTITIS media). Trop J Ophthalmol Otolaryngol.2019;4(2):131-136.doi: 10.17511/jooo.2019.102.11 